\title{
Dysplasia and carcinoma in longstanding ulcerative colitis: an endoscopic and histological surveillance
} programme

\author{
M Leidenius, I Kellokumpu, A Husa, M Riihelä, P Sipponen
}

\begin{abstract}
From 1976 to 1989 a total of 66 patients with longstanding ulcerative colitis were entered in a colonoscopic surveillance programme in order to detect dysplasia. Thirty patients had extensive or total ulcerative colitis and 36 left sided colitis. The median duration of the disease at the end of the follow up was 15.0 years. Altogether 182 colonoscopies $(2 \cdot 8$ per patient), each involving approximately 20 biopsies from different sites of the colon, were performed. In the total or extensive colitis group, five patients had low grade and one patient had high grade dysplasia. In the left sided colitis group, three patients had low grade dysplasia. In three patients low grade dysplasia was detected in a macroscopic lesion or mass of colonic mucosa. Sixty per cent of the dysplasia specimens were from the right colon. The incidence of dysplasia was higher in patients with extensive colitis and increased with the duration of the disease. None of the patients have so far developed colorectal carcinoma. Our results indicate that a colonoscopic surveillance programme is a safe alternative to prophylactic colectomy in longstanding ulcerative colitis.
\end{abstract}

Patients with ulcerative colitis have an increased risk of developing colorectal carcinoma. The risk increases with the duration of the disease and is greater in patients with total or extensive colitis. ${ }^{12}$ However, the magnitude of the risk is difficult to assess. Gyde et al reported the cumulative incidence of colorectal carcinoma among patients with extensive colitis to be $7 \cdot 2 \%$ at 20 years and $16.5 \%$ at 30 years from the onset of the disease. ${ }^{3}$

Because dysplasia usually precedes colorectal carcinoma in inflammatory bowel disease, colonoscopy has been proposed as a way of identifying patients with a particular risk of developing colorectal carcinoma by obtaining histological evidence of dysplastic mucosal changes. ${ }^{45}$ The aim of this study was to assess the development of dysplasia and colorectal carcinoma in patients with longstanding ulcerative colitis and evaluate the usefulness and the safety of routine colonoscopic surveillance.

\section{Patients and methods}

PATIENTS

Altogether 119 patients with ulcerative colitis were examined by colonoscopy from 1976 to
1989 at the Fourth Department of Surgery, Helsinki University Central Hospital, which is one of the referral centres of the province of Uusimaa. The diagnosis of ulcerative colitis was made on the basis of histological findings and endoscopic and radiological appearance of the colon and rectum.

All patients with ulcerative colitis who already had colorectal carcinoma at the time of admission to the hospital were excluded from the study. Patients with haemorrhagic proctitis were also excluded, as were patients who were referred to the department because of some specific complication of ulcerative colitis but were otherwise observed and treated at another hospital.

Sixty six of the 119 patients, who had had ulcerative colitis for seven years or longer were entered in the surveillance programme. The surveillance started in 1976 or at the time of a patient's first colonoscopy and ended in 1989 or when a patient underwent proctocolectomy. Two patients died of causes unrelated to ulcerative colitis. Four patients were followed up by another hospital after their entry in the programme and three patients were lost to follow up.

\section{Methods}

The extent of ulcerative colitis was evaluated on the bases of the endoscopic and radiological appearance of the large bowel. ${ }^{6}$ Patients who had ulcerative colitis proximal to the splenic flexure of the colon were considered to have extensive colitis while the rest were considered left sided colitis.

\section{COLONOSCOPY}

The patients underwent colonoscopic examination annually or every second year after they had had ulcerative colitis for seven years. Colonoscopy was repeated after a shorter interval if considered necessary because of dysplastic or indefinite findings. Each examination involved approximately 20 routine biopsies from different sites of the colorectum. Additional biopsies were taken if macroscopic lesions were found. Patients who underwent colectomy with ileorectal anastomosis during the programme were followed up by sigmoidoscopy.

Altogether 182 colonoscopies ( $2 \cdot 8$ per patient) were performed under the surveillance programme. The caecum was reached in $84 \%$ of the colonoscopies. There were no complications such as perforation or bleeding related to colonoscopy. 


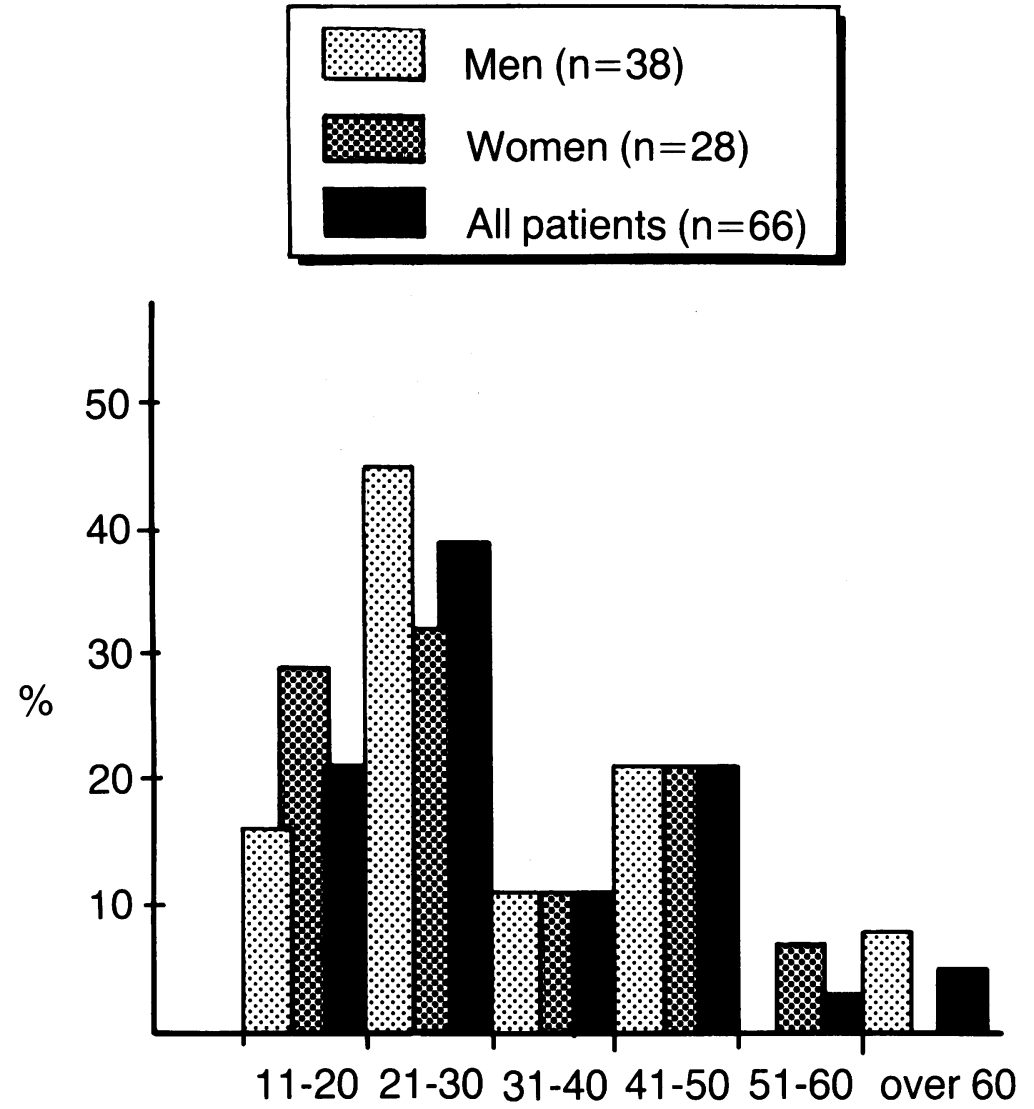

Age (years)

Figure 1: Age and sex distribution of the patients at the time of diagnosis of ulcerative colitis.

HISTOLOGY

All biopsy specimens were first assessed at the Department of Pathology of the University of Helsinki and re-evaluated blindly by two pathologists (MR and PS). The grading of dysplasia was made according to the criteria and principles presented by the IBD Study Group. ${ }^{5}$ Thus, three main categories were recognised: biopsies that were negative, indefinite or positive for dysplasia. The indefinite group was further divided into three subgroups: biopsies probably negative, unknown or probably positive for dysplasia. Biopsies positive for dysplasia were subclassified into low grade or high grade dysplasia. Lesions with an adenomatous pattern were also included in definite dysplasia, as it is difficult to distinguish between adenoma and dysplasia in ulcerative colitis.

\section{STATISTICAL METHODS}

The statistical analyses used the $\chi^{2}$ test and Student's $t$ test.

\section{SURGERY}

Indications for surgery consisted of failure of medical therapy, suspected malignancy (stricture, radiologically diagnosed tumour or dysplasia) and longstanding extensive colitis. Most of the patients operated on had more than one indication for surgery.

It is noteworthy that $67 \%$ of the operations were performed before 1983 when the classification of the IBD Study Group was published.

\section{Results}

PATIENTS

Thirty eight of the 66 patients with longstanding ulcerative colitis were men and 28 were women. Thirty of the patients (46\%) had extensive or total colitis and 36 (54\%) had left sided colitis. The median age of the patients with extensive colitis at the time of the diagnosis was $27 \cdot 5$ (mean (SEM) $31 \cdot 8(11.9)$ ) years and 27.5 (mean (SEM) $31 \cdot 4(13 \cdot 2)$ ) years among the patients with leftsided colitis. (Fig 1) The median duration of ulcerative colitis was 15.0 (mean (SEM) 16.0 $(6 \cdot 0)$ ) years at the end of the surveillance programme.

\section{DYSPLASIA}

Originally dysplasia was classified as mild, moderate or severe by 'routine' pathologists. According to the initial evaluations 20 of the 66 patients appeared to have dysplasia in a total of 58 specimens. When the specimens were reexamined and classified according to the criteria of the IBD Study Group by two more experienced pathologists (MR and PS), 43 of the 58 originally dysplastic findings were regarded as not showing definite dysplasia. Fourteen of those 43 specimens were subsequently classified as indefinite and 29 as negative for dysplasia. Thus, according to the experienced pathologists only nine patients (14\%) and a total of 15 specimens were considered to show definite dysplasia.

Only one patient had high grade dysplasia whereas eight patients had low grade dysplasia (Table I). Three patients had low grade dysplasia found in a macroscopic lesion or mass. In seven (six patients with low grade and one with high grade dysplasia) of the nine patients the dysplastic changes were not re-encountered in subsequent colonoscopies. Dysplasia was found in 15 biopsy specimens. Nine of these $(60 \%)$ were taken from the right side and six $(40 \%)$ from the left side of the colorectum (Table II).

In addition, five patients had one or several biopsies classified as probably positive for dysplasia, nine patients as unknown for dysplasia and eleven patients as probably negative for dysplasia. Thus, a total of $25(38 \%)$ patients had findings indefinite for dysplasia at least on one occasion (Table I). None of the patients developed colorectal carcinoma during the surveillance programme.

The cumulative incidence of dysplasia findings during the follow up as calculated by life table methods is shown in Figure 2. The incidence of dysplasia was $20 \%$ in the extensive or total colitis group and $8 \%$ in the left sided colitis group $\left(\chi^{2}=1.891, \mathrm{~ns}\right)$. The incidence of dysplasia was $16 \%$ in men and $11 \%$ in women $\left(\chi^{2}=0 \cdot 353, \mathrm{~ns}\right)$.

The mean (SEM) age at the time of diagnosis of ulcerative colitis was $44.9(16.8)$ years among patients with dysplasia and $29.5(10.5)$ years among patients who did not exhibit dysplasia during the surveillance programme $(t=3 \cdot 735$, $\mathrm{p}<0.003$ ). 
TABLE I Findings of dysplasia among 66 patients with longstanding ulcerative colitis

\begin{tabular}{|c|c|c|c|c|c|c|c|}
\hline & $\begin{array}{l}\text { Negative } \\
\text { for } \\
\text { dysplasia }\end{array}$ & $\begin{array}{l}\text { Probably } \\
\text { negative } \\
\text { for } \\
\text { dysplasia }\end{array}$ & $\begin{array}{l}\text { Unknown } \\
\text { for } \\
\text { dysplasia }\end{array}$ & $\begin{array}{l}\text { Probably } \\
\text { positive } \\
\text { for } \\
\text { dysplasia }\end{array}$ & $\begin{array}{l}\text { Low } \\
\text { grade } \\
\text { dysplasia }\end{array}$ & $\begin{array}{l}\text { High } \\
\text { grade } \\
\text { dysplasia }\end{array}$ & Carcinoma \\
\hline $\begin{array}{l}\text { Left sided colitis } \\
\text { Total colitis }\end{array}$ & $\begin{array}{r}23 \\
9\end{array}$ & $\begin{array}{l}5 \\
6\end{array}$ & $\begin{array}{l}3 \\
6\end{array}$ & $\begin{array}{l}2 \\
3\end{array}$ & $\begin{array}{l}3(1)^{\star} \\
5(2)^{\star}\end{array}$ & $\begin{array}{l}0 \\
1\end{array}$ & $\begin{array}{l}0 \\
0\end{array}$ \\
\hline
\end{tabular}

^The figure in parenthesis indicates the number of patients with dysplasia in a macroscopic lesion or mass.

TABLE II Distribution of dysplasia in the colon and rectum in 66 patients with longstanding ulcerative colitis

\begin{tabular}{lllllll}
\hline & Caecum & $\begin{array}{l}\text { Ascending } \\
\text { colon }\end{array}$ & $\begin{array}{l}\text { Transverse } \\
\text { colon }\end{array}$ & $\begin{array}{l}\text { Descending } \\
\text { colon }\end{array}$ & $\begin{array}{l}\text { Sigmoid } \\
\text { colon }\end{array}$ & Rectum \\
\hline $\begin{array}{l}\text { No of biopsy specimens } \\
\text { with dysplasia }\end{array}$ & 5 & 0 & 4 & 3 & 0 & 3 \\
\hline & $60 \%$ & & & $40 \%$ & \\
\hline
\end{tabular}

The median duration of ulcerative colitis at the end of the follow up was $15 \cdot 0$ (mean (SEM) $15 \cdot 9$ (5.9)) years among patients who did not develop dysplasia and $17 \cdot 0$ (mean (SEM) $16 \cdot 6(7 \cdot 0)$ ) years among patients who developed dysplasia during the surveillance programme.

\section{SURGERY}

Twelve patients (18\%) were operated on because of ulcerative colitis. Six patients were operated on because of longstanding extensive colitis (prophylactic operation); five of these six patients also had other indications for surgery (failure of medical therapy, stricture of colon, or radiologically suspected tumour). One patient was operated on because of low grade dysplasia and difficulties in performing surveillance colonoscopies; she had findings unknown for dysplasia in her operative specimens, but no definitive dysplasia was found. The remaining five patients were operated on because of poor response to medical therapy or radiologically suspected tumour.

Six proctocolectomies were performed: three using Brooke's ileostomy, two using Kock's ileostomy and one using the pelvic pouch method. Three subtotal colectomies (one with ileostomy and two with ileorectostomy) and three colonic resections were also performed (Table III): All six patients continued with the surveillance programme. The median duration of their follow up after the operation was 6.0 (mean (SEM) 6.7 (4.7)) years. None of the patients operated developed subsequent dysplasia or carcinoma of the colon or rectum spared at the operation.

\section{Discussion}

In previous reports the incidence of carcinoma in extensive longstanding ulcerative colitis has been $1 \cdot 4-3 \cdot 2 \%^{7-11}$ and $1 \cdot 4-1 \cdot 6 \%$ in the reports including patients with both left sided and extensive colitis $^{12}{ }^{13}$ (Table IV). According to the incidence of carcinoma in previous studies, one patient with carcinoma should have been found among the 66 patients in the present study. However, no carcinoma was found, maybe due to the small number of the patients studied or the relatively short duration of ulcerative colitis (median 15.0 years).

The incidence of dysplasia found in this study $(14 \%)$ is in close agreement with previous reports. ${ }^{7-13}$ (Table IV.) However, only two of the nine patients who had dysplasia in at least one specimen, had dysplasia also in further examinations. In three of the nine patients (two with low grade and one with high grade dysplasia), the findings were indefinite for dysplasia, and in two patients there was no dysplasia in further colonoscopies. One of the nine patients had low grade dysplasia on one occasion and was operated on because of problems encountered in performing colonoscopies. The last of the nine patients who had dysplasia also showed low grade dysplasia in a control colonoscopy performed after the endpoint of the surveillance programme. It was also there in previous studies ${ }^{7114}$ that dysplasia found at one examination was often not reencountered in further colonoscopies. The low rate of persistent dysplasia in the present study may be due to sampling errors, difficulties in assessing dysplasia or true regression of dysplasia as suggested by Collins et al. ${ }^{\text {15 }}$

Of the 58 preliminary dysplastic findings only 15 were dysplastic according to the more experienced pathologists. Of the remaining 43 initial dysplastic findings, 14 were subsequently classified as indefinite and 29 as negative for dysplasia. Only three specimens originally negative for dysplasia turned out to be dysplastic upon reexamination. These discrepancies between pathologists as well as the high proportion of findings indefinite for dysplasia reflect the difficulty of assessing dysplasia, indicating that at least two independently working experienced pathologists must agree that a patient has dysplasia in a colonoscopic biopsy before a decision to perform a proctocolectomy is made. New objective markers for selecting patients for prophylactic colectomies are required in clinical practice.

Discrete adenomas of the colon and rectum are common in non-colitic patients and therefore can be expected to occur in some patients with ulcerative colitis. Such adenomas pose problems, in that it may be impossible to distinguish them from polypoid areas of dysplasia related to ulcerative colitis. In younger patients with ulcerative colitis, polypoid lesions tend to be regarded as dysplasia in a macroscopic lesion and thus express a risk of developing or already having a carcinoma. In older patients the adenomas are more likely to be unrelated to ulcerative colitis and treated by simple polypectomy if no dysplasia is found in the mucosa adjacent to the adenoma. ${ }^{58}$

TABLE III Surgical procedures on 12 of the 66 patients with longstanding ulcerative colitis

\begin{tabular}{ll}
\hline & No of procedures \\
\hline Proctocolectomy with: & \\
Brooke's ileostomy & 3 \\
Pelvic pouch & 1 \\
Kock's ileostomy & 2 \\
Subtotal colectomy with: & 1 \\
$\quad$ Ileostomy & 2 \\
Ileorectal anastomosis & 3 \\
\hline
\end{tabular}




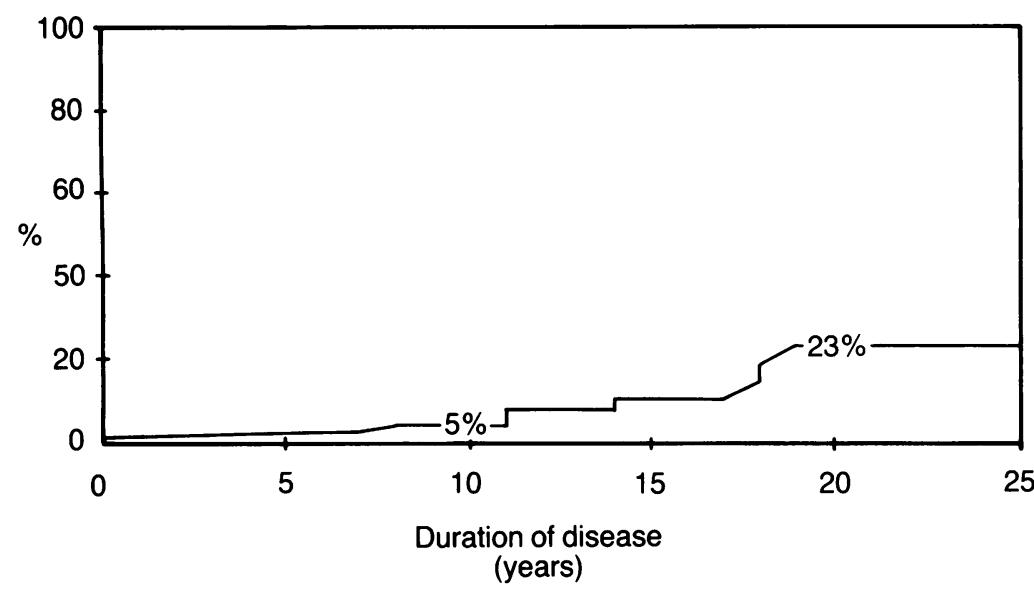

Figure 2: Cumulative incidence of dysplasia in 66 patients with longstanding ulcerative colitis.

In the present study three patients had low grade dysplasia in a macroscopic lesion. One of them (male, 65 years old) had a polypoid lesion removed by polypectomy when entering the surveillance programme. During the colonoscopic surveillance of seven years no dysplasia has been re-encountered. His adenoma has been regarded as unrelated to ulcerative colitis. The second one (female, 79 years old) had had ulcerative colitis for 28 years when dysplasia was encountered in a polypoid lesion which was treated by polypectomy. She had also had dysplasia in the flat mucosa three years before the polypectomy. Proctocolectomy has been advised several times but the patient has refused. No dysplasia was found in her last colonoscopy, which was made one year after the polypectomy. The third patient with dysplasia in a macroscopic lesion (female, 61 years old) had dysplasia found in a plaque-like lesion in the caecum after having ulcerative colitis for 18 years. She continued the colonoscopic follow up with shorter intervals. Dysplasia was re-encountered in the flat mucosa of the caecum in the next colonoscopy, but in the last examination no dysplasia was found despite the numerous specimens taken. In her case surgical treatment has already been considered and is advisable, if dysplasia is re-encountered again.

In some previous reports ${ }^{16}{ }^{17}$ it has been proposed that the younger a patient is at the onset of

TABLE IV Incidence of dysplasia and colorectal cancer in patients with longstanding ulcerative colitis

\begin{tabular}{|c|c|c|c|c|c|}
\hline \multirow[b]{2}{*}{ Study } & \multirow{2}{*}{$\begin{array}{l}\text { No of patients } \\
\text { with colitis }\end{array}$} & \multirow{2}{*}{$\begin{array}{l}\text { Dysplasia (total) } \\
\text { colitis }(\%)\end{array}$} & \multicolumn{2}{|c|}{ Dysplasia $(\%)$} & \multirow{2}{*}{$\begin{array}{l}\text { Cancer } \\
\%\end{array}$} \\
\hline & & & Left-sided & Extensive & \\
\hline $\begin{array}{l}\text { Rosenstock et al, } \\
\text { Cleveland }\end{array}$ & 248 & - & - & 24 & $2 \cdot 4$ \\
\hline $\begin{array}{l}\text { Brorström et al,12 } \\
\text { Stockholm }\end{array}$ & 71 & 13 & 7 & 17 & $1 \cdot 4$ \\
\hline $\begin{array}{l}\text { Blackstone et al }{ }^{,} \\
\text {Chicago }\end{array}$ & 112 & - & - & 35 & $2 \cdot 7^{\star}$ \\
\hline $\begin{array}{l}\text { Manning et al, } \\
\text { Leeds }\end{array}$ & $110^{\star}$ & - & - & $31^{\star}$ & $2 \cdot 0^{\star}$ \\
\hline $\begin{array}{l}\text { Waye, } \\
\text { New York }\end{array}$ & 88 & - & - & 8 & $3 \cdot 2$ \\
\hline $\begin{array}{l}\text { Rutegård et al, }{ }^{13} \\
\text { Ornsköldsvik }\end{array}$ & $60+$ & 15 & 3 & $18 \dagger$ & $1.6+$ \\
\hline $\begin{array}{l}\text { Löfberg et al," } \\
\text { Stockholm }\end{array}$ & 72 & - & - & 19 & $1 \cdot 4$ \\
\hline Present study & 66 & 14 & 8 & 20 & 0 \\
\hline
\end{tabular}

^Patients with suspected colorectal carcinoma based on radiography of the colon before the first colonoscopy are excluded.

tOnly patients with ulcerative colitis for over 10 years' duration are included. ulcerative colitis the higher the risk of developing a colorectal carcinoma. Long duration of disease and early age at onset are interrelated. The present study failed to confirm that patients who were younger at the time of diagnosis of ulcerative colitis would be more prone to develop dysplasia. On the contrary, patients who developed dysplasia were older at the time of diagnosis of ulcerative colitis than those who did not develop dysplasia. Lashner et al. ${ }^{18}$ made the same observation in their study. The significance and the biological background of this phenomenon is obscure. In the present study it may be partly explained by the small patient series and short duration of the follow up.

Previous reports have shown that the extent of the colitis increases the risk of colorectal carcinoma. ${ }^{12}$ There are only a few reports of colorectal carcinoma in patients with left sided ulcerative colitis. ${ }^{13}$ It is supposed that the carcinoma risk is lower in patients with left sided ulcerative colitis or that patients with left sided colitis develop colorectal carcinoma later than patients with total or extensive colitis. ${ }^{1}$ In the present study patients with extensive or total colitis had a higher incidence of dysplasia (20\%) than those with left sided colitis (8\%) but the difference was not statistically significant. Brorstöm $e t a l^{12}$ reported a similar incidence of dysplasia in extensive and left sided colitis.

Patients with longstanding extensive ulcerative colitis have an increased risk of developing colorectal carcinoma compared with the average population. The exact risk is difficult to assess; it is thought that the risk is too low to justify routine prophylactic colectomy after 10 years from the onset of extensive ulcerative colitis but too high to be ignored. In the 1970 s it was recommended that patients who have had widespread ulcerative colitis for 7-10 years should enter a surveillance programme designed to detect dysplasia.

The safety and cost benefit of surveillance programmes are difficult to estimate because of lack of controlled studies, which in turn would be both impractical and unethical. In the present study none of the patients developed colorectal carcinoma during the follow up. There were no complications related to colonoscopies and the surveillance programme was well received by the patients; only three patients were lost to follow up.

The present study confirms the importance of colonoscopy in a surveillance programme. Sixty per cent of the dysplastic findings were located in the right side of the colorectum and so out of the reach of fibre optic sigmoidoscopy. The distribution of dysplasia in the present study resembles the distribution of colorectal carcinoma in ulcerative colitis reported by Edling et al. ${ }^{19}$ Previous studies $^{7-1012}$ and the present results show that, in spite of their restrictions, surveillance programmes present a safe and useful alternative to a prophylactic colectomy. If routine prophylactic proctocolectomies had been carried out in the present programme at 10 years after the onset of total or extensive ulcerative colitis, as recommended in the past, 29 of the 66 patients would have undergone a proctocolectomy.

The IBD Study Group has given explicit 
recommendations for further action according to the findings in colonoscopic specimens. ${ }^{5}$ The relative risk of colorectal carcinoma is high in younger patients compared to the low incidence of colorectal carcinoma in a young control population. Their absolute risk of developing a colorectal carcinoma is also supposed to be higher than among older patients because they will have a longer duration of disease and more years to live to develop a carcinoma. It may be therefore advisable to perform prophylactic operation in young patients with more liberal indications, keeping in mind that they will probably be suitable for a sphincter-saving proctocolectomy. The risk of carcinoma in older patients is close to that of control populations of the same age. Therefore these patients could have control colonoscopies at longer intervals and patients older than 75 years could perhaps be excluded from surveillance programmes.

In conclusion, the present study shows that the incidence of dysplasia increases with the duration of ulcerative colitis and that the distribution of dysplasia renders fibre optic sigmoidoscopy insufficient in detecting dysplasia. Colonoscopy appears to be essential to a surveillance programme. As none of the patients studied developed colorectal cancer during the surveillance, the risk of missing a cancer before it becomes incurable seems to be low. For patients with longstanding ulcerative colitis, an endoscopic and histological surveillance programme is considered to be a safe alternative to a prophylactic proctocolectomy.

This stùdy was supported by a grant from the Finska Läkaresällskapet.
1 Greenstein AJ, Sachar DB, Smith $\mathrm{H}$ et al. Cancer in universal and left-sided ulcerative colitis: factors determining risk. Gastroenterology 1979; 77: 290-4.

2 Kewenter J, Ahlman H, Hulten L. Cancer risk in extensive ulcerative colitis. Ann Surg 1978, 188: 824-7.

3 Gyde SN, Prior P, Allan RN et al. Colorectal cancer in ulcerative colitis: a cohort study of primary referrals from ulcerative colitis: a cohort study of

4 Morson BC, Pang LSC. Rectal biopsy as an aid to cancer control in ulcerative colitis. Gut 1967; 8: 423-34.

5 Riddell RH, Goldman H, Ranshoff DF et al. Dysplasia in inflammatory bowel disease: standardized classification with provisional clinical applications. Hum Pathol 1983; 11 931-66.

6 Williams CB. Determining the extent of the colitis. In Allan RN, Keighley MRB, Alexander-Williams J, Hawkins C, eds. Inflammatory bowel disease. New York: Churchil Livingstone, 1983: 212 .

7 Rosenstock E, Farmer RG, Petras R, Sivak Jr MV, Rankin $\mathrm{GB}$, Sullivan BH. Surveillance for colonic carcinoma in ulcerative colitis. Gastroenterology 1985; 89: 1342-6.

8 Blackstone MO, Riddell RH, Rogers BHG, Levin B. Dysplasia-associated lesion or mass (DALM) detected by colonoscopy in long-standing ulcerative colitis: an indication fo colectomy. Gastroenterology 1981; 80: 366-74

9 Manning AP, Bulgin OR, Dixon MF, Axon ATR. Screening by colonoscopy for colonic epithelial dysplasia in inflam matory bowel disease. Gut 1987; 28: 1489-94

10 Waye JD. Dysplasia and ulcerative colitis - a colonoscopic study. Scand $\mathcal{F}$ Gastroenterol $1983 ; 18$ suppl $88: 44-7$.

11 Löfberg R, Brorström O, Karlen P, Tribukait B, Öst Å Colonoscopic surveillance in longstanding ulcerative colitisa fifteen year follow-up study. Acta Chir Scand 1989; 522 (suppl): 1-45.

12 Brorström O, Löfberg R, Öst $\AA$, Reichard H. Cancer surveillance of patients with longstanding ulcerative colitis: clinical, endoscopical, and histological study. Gut 1986; 27 : clinical, endr.

13 Rutegård J, Åhsgren L, Stenling R, Janunger KG. Ulcerative colitis. Cancer surveillance in an unselected population. Scand F Gastroenterol 1988; 23: 139-45.

14 Lennard-Jones JE, Morson BC, Ritchie JK, Williams CB Cancer surveillance in ulcerative colitis. Experience over 15 years. Lancet 1983; ii: 149-52.

15 Collins RH, Feldman M, Fordtran JS. Colon cancer, dysplasia and surveillance in patients with ulcerative colitis. A critical review. N Engl F Med 1987; 25: 1654-8.

16 Devroede GJ, Taylor WF, Sauer WG, Jackson R, Stickler G. Cancer risk and life expectancy of children in ulcerative Cancer risk and life expectancy of child
colitis. NEngl F Med 1971; 285: 17-21.

17 Edwards FC, Truelove SC. The course and prognosis of ulcerative colitis. Part IV. Carcinoma of the colon. Gut 1964 5: 1-22.

18 Lashner BA, Silverstein MD, Hanauer SB. Hazard rates for dysplasia and cancer in ulcerative colitis. Results from surveillance program. Dig Dis Sci 1989; 34: 1536-41.

19 Edling NPG, Eklöf O. Radiological findings and prognosis in ulcerative colitis. Acta Chir Scand 1961; 121: 299-308. 